\title{
Raman espektroskopiaren erabilgarritasunaren azterketa elikagaien koloratzaileak kuantifikatzeko
} (Study of the usefulness of Raman spectroscopy to quantify food dyes)

\author{
Iñaki Vázquez-de la Fuente*1, Nagore Prieto-Taboada ${ }^{2}$, Miren Ostra-Beldarrain ${ }^{2}$, \\ Juan Manuel Madariaga ${ }^{1}$
}

${ }^{1}$ Kimika Analitikoa, Zientzia era Teknologia Fakultatea (UPV/EHU)

${ }^{2}$ Kimika Aplikatua, Kimika Fakultatea (UPV/EHU)

\begin{abstract}
LABURPENA: Raman espektroskopia metodo analitiko ez-suntsikorra da, aurre-tratamendurik behar izan gabe laginak analizatzea ahalbidetzen duena. Teknika honek eskaintzen dituen abantailak kontuan hartuz, lan honetan teknika honek elikagaikoloratzaileak analizatu eta kuantifikatzeko eskaintzen dituen aukerak aztertu dira, industria-mailan teknikak izan dezakeen erabilgarritasuna ikertzeko asmoz. Lehenik eta behin, bi laser ezberdinekin (785 eta $532 \mathrm{~nm}$ ) elikaduran ohikoak diren zenbait konposatu eta koloratzaileren datu-basea egin da, Raman seinale egokia duten koloratzaileak identifikatzen lagundu duena. Horren ondoren, analisi kuantitatiboa egiteko, aldagai bakarreko erregresio lineala eta minimo karratu partzialen erregresioa (Partial Least Squares Regression, PLS) erabili dira Raman seinalea kontzentrazioarekin erlazionatzeko. Emaitza positiboak lortu dira, batez ere E133 koloratzailearentzat, zeren eta analito honentzat lortutako kuantifikazio-muga (LOQ) koloratzaile honentzat Europar Batasunak ezarritako gehieneko kontzentrazioaren $(200 \mathrm{mg} / \mathrm{kg})$ azpitik baitago. Azkenik, kalibrazioa hobetzeko aukera aztertu da, Gainazalak Anplifikaturiko Raman Espektroskopia erabiliz (Surface Enhanced Raman Spectroscopy, SERS). Kasu honetan seinaleen intentsitatea handitu bada ere, ez da aurkitu seinalearen intentsitatearen eta kontzentrazioaren arteko erlazio linealik. Hori guztia kontuan hartuta, Raman espektroskopiaren bidezko koloratzaileen analisi kuantitatibora egindako hurbilketa egokia izan da, literaturan jasotako emaitzak hobetuz. Beraz, lan hau etorkizuneko ikerketetarako oinarritzat erabil daiteke, koloratzaileak lagin-tratamendurik gabe modu azkar eta merkean analizatzeko.
\end{abstract}

HITZ GAKOAK: Raman espektroskopia, analisi kuantitatiboa, kimiometria, koloratzaileak, E133.

\begin{abstract}
Raman spectroscopy is a non-destructive analytical method that allows samples to be analyzed without the need for pre-treatment. Taking these advantages into account, in this work we studied the possibility of using this technique when determining and quantifying food dyes, with the aim of investigating its usefulness in the industry. First, a database of dyes and usual compounds in food with two different lasers (785 and $532 \mathrm{~nm}$ ) was developed that also helped identify dyes with better Raman response. After this, for the quantitative analysis the calibration with univariable and multivariable regression (Partial Least Squares regression, PLS) was carried out in order to relate the intensity of the Raman signal with the variation of concentration, achieving promising results, especially for E133 dye that has quantification limits (LOQ) below the maximum concentration allowed by the European Union $(200 \mathrm{mg} / \mathrm{kg})$ for this dye. Finally, the possibility of improving the calibration was evaluated using surface enhanced Raman Spectroscopy (SERS), with which more intense signals were obtained but did not maintain a relationship between the signal strength and the concentration. With all this in mind, this approach to quantitative dye analysis by Raman spectroscopy has been promising, improving the results of the literature, and can serve as a basis for future research for the analysis of dyes without sample treatment, quickly and at a low cost.
\end{abstract}

KEYWORDS: Raman spectroscopy, quantitative analysis, chemometrics, food dyes, E133.

* Harremanetan jartzeko / Corresponding author: Iñaki Vázquez-de la Fuente. Kimika Analitikoa, Zientzia era Teknologia Fakultatea, UPV/EHU, Sarriena Auzoa (48940-Leioa, Bizkaia). - jivazquez002@ikasle.ehu.eus - https://orcid.org/0000-00027131-4168

Nola aipatu / How to cite: Vázquez-de la Fuente, Iñaki; Prieto-Taboada, Nagore; Ostra-Beldarrain, Miren; Madariaga, Juan Manuel (2022). "Raman espektroskopiaren erabilgarritasunaren azterketa elikagaien koloratzaileak kuantifikatzeko». Ekaia, 42, 2022, 155-172. (https://doi.org/10.1387/ekaia.22954).

Jasotze-data: 2021, ekainak 30; Onartze-data: 2022, urtarrilak 17.

ISSN 0214-9001 - elSSN 2444-3255 / (c) 2022 UPV/EHU

(i) $(-)$ Lan hau Creative Commons Aitortu-EzKomertziala-LanEratorririkGabe 4.0 Nazioartekoa

(c) 
Iñaki Vázquez-de la Fuente, Nagore Prieto-Taboada, Miren Ostra-Beldarrain, Juan Manuel Madariaga

\section{SARRERA}

Elikagaien industriak gehigarri ugari erabiltzen ditu elikagaietan, haien ezaugarriak aldatzeko helburuarekin. Gehigarriak elikagaien osagaien zerrendan zehaztu behar dira, bertan betetzen duten funtzioa adieraziz. Beren izenaren edo E zenbakiaren arabera zerrendatuta egon daitezke, hori baita Europar Batasunean baimentzen den kodea [1]. Era berean, koloratzaileen erabilera zorrotz kontrolatzen dute, besteak beste, Kontsumoaren, Elikagaien Segurtasunaren eta Nutrizioaren Espainiako Agentziak (AECOSAN), hain zuzen ere Europako araudiak aplikatzeaz arduratzen den agentziak. Hala ere, koloratzaile jakin batzuen erabileraren murrizketak malguak dira, eta dagokien araudia aldakorra izan daiteke gehigarria duen elikagaiaren arabera [2].

Horregatik guztiagatik, koloratzaileak determinatu eta kuantifikatzea elikagaien industriako analisi ohikoenetako bat da. Gehigarri horiek kontrolatzeko, ISO (Nazioarteko Normalizazio Erakundea) metodo estandarrak erabiltzen dira, eta horretarako ohiko prozedura da koloratzaile bakoitzari dagokion uhin-luzera jakinean absorbantzia neurtzea $1 \mathrm{~cm}$-ko zelda batean [3]. ISO metodoez gain, industrian metodo analitiko alternatiboak bilatzen dira, azkarragoak, sentikorragoak, ekonomikoagoak, lagin-tratamendu txikiagoa eskatzen dutenak eta/edo suntsitzaileak ez direnak. Horregatik, hurbileko infragorri-espektroskopia (NIR) [4] bezalako teknologiak erabiltzen dira, kimiometriari esker aurrerapen handia izaten ari dena, zeren eta espektroetatik informazio kualitatibo eta kuantitatibo handia lortzea ahalbidetzen baitu. Bestelako teknika alternatiboak ere aurrera egiten ari dira, hala nola irudi digitalaren analisia, espektrofotometroen ordez guztion eskura dauden gailuak erabiltzeko aukera eskaintzen duena [5, 6].

Analisi alternatibo horietarako etorkizun handiko tekniketako bat Raman espektroskopia da, literaturan elikagaien koloratzaile batzuk determinatu eta kuantifikatzeko erabili dena [7-9]. Lan hauetan Gainazalak Anplifikaturiko Raman Espektroskopia (Surface Enhanced Raman Spectroscopy, SERS) erabili ohi da; izan ere, teknika honek substantzia hauen analisiaren sentsibilitatea handitu dezake [7], eta laginetan kontzentrazio baxuetan egon ohi diren koloratzaileen analisia ahalbidetu. Europako legeak $50-1.000 \mathrm{mg} / \mathrm{L}$-tan ezartzen ditu kontrolatu behar diren koloratzaileen kontzentrazioen mugak [10].

Egitura molekular bakoitzak Raman espektro bereizgarri bat du, posizio eta intentsitate oso espezifikoetako bandak dituena [7], sentikortasun handiko analisi kualitatibo bat ahalbidetu, eta konposatu polimorfoak bereizteko aukera eskaintzen duena [11]. Gainera, Raman espektroskopiak analisi kuantitatiboa egiteko aukera ere ematen du, intentsitatearen eta kontzentrazioaren arteko erlazio lineala aurkezten baitu [3]. Hala ere, Raman kuantifikazioa konplexua da parametro instrumentalen mendekotasuna- 
gatik, seinaleen maskaratze fenomenoengatik edo analizatu nahi diren laginen heterogeneotasunagatik; horregatik, kasu askotan datuak tratatzeko erreminta konplexuak erabili behar dira [12]. Nolanahi ere, Raman espektroskopia potentzial handiko teknika da, eta horregatik ikerketa ugari egiten dira hainbat arlotan teknika hau aplikatzeko [13-18].

Raman espektroskopia erabiliz determinazio arrakastatsu bat egiteko, analizatu nahi den laginak izan ditzakeen osagaien espektroekin datu-base bat osatzea komeni da. Literaturan badaude sarbide libreko datu-base batzuk [19], baina gutxi eta nahiko mugatuak dira; beraz, normalean laborategi bakoitzak bere datu-base propioa egiten du.

Hori guztia kontuan hartuta, lan honetan Raman espektroskopiaren ahalmena ebaluatzen da elikagaien koloratzaileak kuantifikatzeko, industrian erabiltzen diren metodologien alternatiba gisa. Horretarako, lehenik eta behin, datu-base bat egin zen intereseko koloratzaileak aukeratzeko; horrez gain elikagai laginetan ohikoak diren beste konposatu batzuen espektroak ere bildu ziren hauek eragin ditzaketen interferentziak aztertzeko. Bestalde, hainbat koloratzaileren analisi kuantitatiborako metodologia garatu zen, eta honen kalitate-parametroak kalkulatu ziren metodoaren balidazioa egiteko.

\section{ESPERIMENTALA}

\subsection{Instrumentazioa}

Raman espektroak neurtzeko, Raman InnoRamTM (B\&WTek) bi espektrometro erabili dira, bi kitzikatze-laser ezberdin dituena (1. taula). Azkenik, espektrometroak CCD detektagailu bat eta mikroskopio bat zituen $(10 \times, 20 \times$ eta $50 \times$ objektiboak). Lan honetan erabilitako objektiboa $\% 50 \times$ izan da. Mikroskopioaren gainean muntatutako mikrozundek ( 0,1 mm-ko fokuratze-eremua) laginean nahi den eremua fokuratzea ahalbidetzen dute mikrokamera baten bidez.

1. taula. Erabilitako laser-iturrien ezaugarriak.

\begin{tabular}{cccc}
\hline Uhin-luzera & $\begin{array}{c}\text { Laser nominala } \\
\text { laginaren azaleran }\end{array}$ & $\begin{array}{c}\text { Tarte espektral } \\
\text { finkoa }\end{array}$ & $\begin{array}{c}\text { Bereizmen } \\
\text { espektrala }\end{array}$ \\
\hline $785 \mathrm{~nm}$ & $255 \mathrm{~mW}$ & $100-3.000 \mathrm{~cm}^{-1}$ & $3.5 \mathrm{~cm}^{-1}$ \\
$532 \mathrm{~nm}$ & $33 \mathrm{~mW}$ & $62-3.750 \mathrm{~cm}^{-1}$ & $5.0 \mathrm{~cm}^{-1}$ \\
\hline
\end{tabular}

Laserraren irteera-potentzia osoaren \% 2 eta \% 20 arteko tarte aldakorra erabili zen laginen deskonposizio termoa saihesteko; esposizio- eta 
Iñaki Vázquez-de la Fuente, Nagore Prieto-Taboada, Miren Ostra-Beldarrain, Juan Manuel Madariaga

metatze-denborak aldatu egin ziren lagin bakoitzaren beharren arabera. Mikroskopioaren kamera ikusteko, Videology softwarea erabili zen; espektroak eskuratzeko, berriz, BWSpec4.02_15. software-paketea erabili zen.

\subsection{Erreaktiboak}

Elikagaien industrian erabili ohi diren koloratzaileetako batzuen espektro-liburutegi bat egin zen, analisi kuantitatiborako koloratzailerik onenak hautatzeko, aztertutako konposatu bakoitzaren banda bereizgarriak identifikatzeko eta aldagai anitzeko kalibraketa egiteko erabili beharreko banden hautaketa errazteko. Aztertu ziren koloratzaileak hauek izan ziren: Tartrazina E102 (\% 87; $\mathrm{C}_{16} \mathrm{H}_{9} \mathrm{~N}_{4} \mathrm{Na}_{3} \mathrm{O}_{9} \mathrm{~S}_{2}$; ROHA EPSA, S.L.), Ponceau Gorria 4R E124 $\left(\mathrm{C}_{20} \mathrm{H}_{11} \mathrm{~N}_{2} \mathrm{Na}_{3} \mathrm{O}_{10} \mathrm{~S}_{3}\right.$; ALDO S.L.U.), Azorrubina E122 $\left(\mathrm{C}_{20} \mathrm{H}_{12} \mathrm{~N}_{2} \mathrm{Na}_{2} \mathrm{O}_{7} \mathrm{~S}_{2}\right.$; ALDO CEPSA E829 S.L.U), Allura Gorria E129 (\% 85; $\mathrm{C}_{18} \mathrm{H}_{14} \mathrm{~N}_{2} \mathrm{Na}_{2} \mathrm{O}_{8} \mathrm{~S}_{2}$; ROHA EPSA, S.L.), Urdin Distiratsua E133 (\% 85; $\mathrm{C}_{37} \mathrm{H}_{34} \mathrm{~N}_{2} \mathrm{Na}_{2} \mathrm{O}_{9} \mathrm{~S}_{3}$; ALDO S.L.U.), Kotxinilla \%50 (\% 50; $\mathrm{C}_{22} \mathrm{H}_{20} \mathrm{O}_{13}$; APASA) eta Berdea (ALDO S.L.U.). Koloratzaile hauek beren kontzentrazioa mugatuta daukate zenbait araudiren bidez, eta, ondorioz, garrantzitsuagoak dira analisi kuantitatiborako [10].

Gainera, elikagai koloreztatuetan ohikoak diren beste gehigarri batzuen espektroak ere lortu ziren, espektroen arteko aldeak behatzeko eta aukeratutako koloratzaileekin izan zitezkeen interferentziak aztertzeko. Aztertutako gehigarriak hauek izan ziren: Kafeina (\% 98,5-101,0; $\mathrm{C}_{8} \mathrm{H}_{10} \mathrm{~N}_{4} \mathrm{O}_{2}$; PanReac), Sorbitol (\% 98; $\mathrm{C}_{6} \mathrm{H}_{14} \mathrm{O}_{6}$; SIGMA), Glukosa (\% 99,5; $\mathrm{C}_{6} \mathrm{H}_{12} \mathrm{O}_{6} ;$ SIGMA), Sakarosa $\left(\mathrm{C}_{12} \mathrm{H}_{22} \mathrm{O}_{11} ;\right.$ Panreac), Fruktosa $\left(\mathrm{C}_{6} \mathrm{H}_{12} \mathrm{O}_{6}\right)$; Azido zitrikoa (\% 99,5; $\mathrm{C}_{6} \mathrm{H}_{8} \mathrm{O}_{7} ;$ PanReac) eta $\mathrm{C}$ bitamina (\% 99,7; $\mathrm{C}_{6} \mathrm{H}_{8} \mathrm{O}_{6} ;$ Panreac). Espektroak 785 eta $532 \mathrm{~nm}$-ko laserrekin neurtu ziren zuzenean konposatu-hautsetan.

Koloratzaileen analisian gerta daitezkeen interferentziak aztertzeko, osagai nagusien analisia egin zen (Principal Component Analysis, PCA), honela koloratzaileen espektroek aztertutako beste gehigarrien espektroekin duten erlazioa aztertu eta haien arteko gainezarpenak analisian eragina izan dezakeen aztertu nahi izan zen. Analisi horretarako, The Unscrambler X (Camo Software) softwarea erabili zen.

\subsection{Kalibraketa lortzea}

Koloratzaile bakoitzaren kalibraketa egiteko kasu bakoitzean espektrorik onena eman zuen laser-iturria erabili zen: E124 eta E122 koloratzaileak $785 \mathrm{~nm}$-ko laserrarekin neurtu ziren, $100-500 \mathrm{mg} / \mathrm{L}$ eta $50-400 \mathrm{mg} / \mathrm{l}-\mathrm{ko}$ kontzentrazio-tartean, hurrenez hurren; E133 koloratzailea, berriz, $532 \mathrm{~nm}-\mathrm{ko}$ laserrarekin, 2-500 mg/l-ko kontzentrazio-tartean.

Laginak prestatzeko koloratzailearen ur-disoluzio baten $30 \mu \mathrm{L}$ tanta Raman seinalerik ematen ez duen kaltzio fluorurozko euskarri baten gai- 
nean jarri zen mikropipetarekin, eta disoluzioa airean lehortzen utzi zen, eraztun itxurako hondakin bat sortu arte [7]. E124 eta E122 koloratzaileen kasuan espektroak eraztunaren kanpoko ertzean neurtu ziren, eta E133 koloratzailearen kasuan, berriz, eraztunaren barruan nahiz kanpoan lortutako kalibraketa alderatu zen. Koloratzaile bakoitzarentzat, kalibraketa osoan zehar mantendu ziren baldintza instrumentalak finkatu ziren (esposiziodenbora eta laserraren intentsitatea).

Bi kalibraketa mota burutu dira: aldagai bakarreko erregresio lineala eta minimo karratu partzialen bidezko erregresioa (Partial Least Squares Regression, PLS). Aldagai bakarreko kalibraketarako, hautatutako bandaren altuera irudikatu zen kontzentrazioaren aurrean, eta horretarako, koloratzaile bakoitzarentzat intentsitate handieneko banda aukeratu zen. Banden altueraren neurketa Omnic 7.2 (Nicolet) softwarearekin egin zen. PLS bidezko kalibraketa The Unscrambler X (Camo Software) softwarearekin egin zen. Kalibraketa mota honetarako aukeratutako koloratzailea E133 izan zen; izan ere, emaitzen atalean xehetasunez deskribatuko denez, kalibraketa aldagai bakarreko kalibraketan erlazio lineal onena izan zuen koloratzailea izanik, bi metodoak alderatu ahal izateko analito aproposa zela erabaki zen. Aldagai anitzeko kalibraketarako koloratzaile honentzat erabilitako espektroak aldagai bakarreko kalibraketarako eraztunaren ertzean neurtutako espektro berberak izan ziren. Azkenik, E133 koloratzailearentzat kontzentrazio ezezaguneko disoluzio bat prestatu zen, kontzentrazio-kalibrazio bi kalibraketen zehaztasuna ebaluatzeko eta alderatzeko.

PLS ereduen egokitasuna eta sendotasuna neurtzeko, kalibrazioaren batezbesteko errore koadratikoaren erroa (Root Mean Square Error of Calibration, RMSEC) eta balidazioaren batezbesteko errore koadratikoaren erroa (Root Mean Square Error of Validation, RMSEV) erabili dira, ekuazio hauen arabera definituak:

$R M S E C=\sqrt{\frac{\sum\left(\hat{y}_{\iota}-y_{i}\right)^{2}}{N_{k a l}}}$ 1. ekuazioa $R M S E V=\sqrt{\frac{\sum\left(\hat{y}_{\iota}-y_{i}\right)^{2}}{N_{v a l}}}$ 2. ekuazioa

Non $\hat{y}_{\iota}$ lagin jakin batentzat PLS ereduak aurresandako kontzentrazioa den, eta $y_{i}$ lagin beraren kontzentrazio teorikoa. $N_{k a l}$ eta $N_{b a l}$ kalibrazioan eta balidazioan erabilitako lagin kopuruak dira, hurrenez hurren.

\subsection{SERS}

Koloratzaileetatik lortutako Raman seinalea hobetzeko asmoz, SERS bidezko Raman analisia egin zen. Horretarako, lehenik eta behin, zilarrezko nanopartikulen (AgNPs) sintesia egin zen, zilar nitratoa \% 99,8 
Iñaki Vázquez-de la Fuente, Nagore Prieto-Taboada, Miren Ostra-Beldarrain, Juan Manuel Madariaga

$\left(\mathrm{AgNO}_{3}\right.$, PanReac) eta sodio zitratoa $\left(\mathrm{Na}_{3} \mathrm{C}_{6} \mathrm{H}_{5} \mathrm{O}_{7}\right)$ erabiliz, literaturan deskribatutako prozedura bati jarraituz [20]. Nanopartikulak zentrifugatu egin ziren, eta gehiegizko likidoaren ultramore-ikusgai espektroa neurtu zen 200-800 nm artean; espektro horren maximoa 390-420 nm artean egoteak adieraziko du sintetizatutako nanopartikulen tamaina egokia dela [21]. Behin nanopartikulak lortuta, euskarri baten gainean (Raman seinalerik gabeko kaltzio fluorurozko euskarria) $15 \mu \mathrm{L} \mathrm{AgNPs} \mathrm{eta} 15 \mu \mathrm{L}$ koloratzaile disoluzio (E133) nahastu ziren, eta tanta homogeneoa eratu zen gainazalean. Ondoren, disoluzioa lehortzen utzi zen eraztun itxurako hondakina sortu arte, eta azkenik Raman espektroak neurtu ziren eraztunaren barnean eta ertzean.

\section{EMAITZAK ETA EZTABAIDA}

\subsection{Koloratzaileen eta beste elikagai-gehigarri batzuen banakako karakterizazioa}

2. taulak aztertutako koloratzaile guztiak eta horiei dagozkien Raman espektroak jasotzen ditu, seinalerik handiena eta fluoreszentziaren interferentzia txikiena eman duen laser-iturria erabiliz lortuak. $785 \mathrm{~nm}$-ko laserrarekin, kolore gorri eta horiko ia kolore guztietako ongi definitutako tontordun espektroak lortu ahal izan ziren, Kotxinilla (E120) koloratzailearentzat izan ezik. $532 \mathrm{~nm}$-ko laserrarekin, Urdin distiratsua (E133) koloratzailea aztertzean ondo definitutako tontor bat baino ez zen lortu espektroan. Horrez gain, Allura Gorria (E129) eta Azorrubina (E122) koloratzaileentzat ere espektroak neurtu ziren, baina kasu hauetan fluoreszentziaren eragina nabarmen handiagoa zen. Oro har, $532 \mathrm{~nm}$-ko laserrak fluoreszentzia handiagoa sortzen zuen koloratzaile laranja eta gorrietan, eta hori normala da, energia handiagoko laserra baita [22].

Karakterizazioaren emaitzak aztertu ondoren, kalibraketa egiteko erabiliko ziren koloratzaileak hautatzeko irizpideak finkatu ziren. Hala, intentsitate handiko eta ondo definitutako tontorrak eta fluoreszentziaren eragin txikia zuen espektro duten koloratzaileak aukeratu ziren kuantifikaziorako. Hain zuzen ere, $785 \mathrm{~nm}$-ko laserrarekin kalibratzeko aukeratutako koloratzaileak E124 eta E122 izan ziren, eta 532 nm-ko laserrarekin, berriz, E133 koloratzailearen kalibraketa egin zen. 
2. taula. Aztertutako konposatuentzat behatutako Raman banden zerrenda.

\begin{tabular}{|c|c|}
\hline Konposatua & Bandak \\
\hline \begin{tabular}{c|} 
E102 \\
$(785 \mathrm{~nm}$ laserra $)$
\end{tabular} & $\begin{array}{l}1600 \mathrm{vs}, 1500 \mathrm{~m}, 1465 \mathrm{w}-\mathrm{m}, 1412 \mathrm{w}, 1357 \mathrm{~s}, 1264 \mathrm{vw}, 1212 \mathrm{w}-\mathrm{m}, 1175 \mathrm{w}-\mathrm{m}, \\
1128 \mathrm{~s}, 1090 \mathrm{w}, 1042 \mathrm{w}, 1005 \mathrm{vw}, 874 \mathrm{w}, 853(\mathrm{sh}), 802 \mathrm{w}, 766 \mathrm{w}, 735 \mathrm{vw}, 707 \mathrm{w}, \\
697 \mathrm{w}, 628 \mathrm{w}, 613 \mathrm{w}, 484 \mathrm{w}\end{array}$ \\
\hline $\begin{array}{c}\text { E124 } \\
(785 \mathrm{~nm} \text { laserra })\end{array}$ & $\begin{array}{l}1573 \mathrm{~s}, 1512 \mathrm{~m}, 1473 \mathrm{vw}, 1455 \mathrm{w}, 1437 \mathrm{~m}, 1420(\mathrm{sh}), 1400 \mathrm{vw}, 1360 \mathrm{vs}, 1298 \mathrm{~m}, \\
1282(\mathrm{sh}), 1237 \mathrm{~s}, 1203 \mathrm{~m}, 1158(\mathrm{sh}), 1145 \mathrm{w}, 1119 \mathrm{vw}, 1043 \mathrm{w}, 942 \mathrm{w}, 692 \mathrm{~m}, \\
612 \mathrm{w}, 580 \mathrm{w}, 500 \mathrm{~s}, 421 \mathrm{w}\end{array}$ \\
\hline \begin{tabular}{c|c} 
E122 \\
(785 nm laserra)
\end{tabular} & $\begin{array}{l}1583(\mathrm{sh}), 1568 \mathrm{~s}, 1550(\mathrm{sh}), 151 \mathrm{~s}, 1444 \mathrm{~s}, 1435(\mathrm{sh}), 1402 \mathrm{w}, 1355 \mathrm{~s}, 1332 \mathrm{w}, \\
1290(\mathrm{sh}), 1274 \mathrm{~s}, 1227 \mathrm{~m}, 1199 \mathrm{w}, 1156 \mathrm{w}, 1108 \mathrm{w}, 1045 \mathrm{~m}, 1000 \mathrm{~m}, 947 \mathrm{w}, \\
726 \mathrm{~m}, 679 \mathrm{~m}, 653 \mathrm{~m}, 556 \mathrm{w}, 530 \mathrm{~m}, 500 \mathrm{~m}, 475(\mathrm{sh}), 467 \mathrm{~s}\end{array}$ \\
\hline $\begin{array}{c}\text { E122 } \\
(532 \mathrm{~nm} \text { laserra })\end{array}$ & $\begin{array}{l}1604 \mathrm{~m}, 1568 \mathrm{~s}, 1564(\mathrm{sh}) \\
1276 \mathrm{~m}, 1230 \mathrm{~m}, 1000 \mathrm{~m}, 6\end{array}$ \\
\hline \begin{tabular}{c|c} 
E129 & \\
$(785 \mathrm{~nm}$ laserra $)$
\end{tabular} & $\begin{array}{l}1610 \mathrm{~m}, 1578 \mathrm{~s}, 1546(\mathrm{sh}), 1494 \mathrm{vs}, 1475(\mathrm{sh}), 1409 \mathrm{vs}, 1380 \mathrm{~s}, 1323 \mathrm{vs}, \\
1268 \mathrm{~s}-\mathrm{vs}, 1222 \mathrm{vs}, 1185 \mathrm{~m}, 1142(\mathrm{sh}), 1127 \mathrm{~m}, 1086 \mathrm{w}, 1075 \mathrm{w}, 1015 \mathrm{w}, 975 \mathrm{~m}, \\
752 \mathrm{~s}, 660 \mathrm{w}, 635 \mathrm{w}, 593 \mathrm{~m}, 491 \mathrm{~s}\end{array}$ \\
\hline $\begin{array}{c}\text { E129 } \\
(532 \mathrm{~nm} \text { laserra })\end{array}$ & $1582 \mathrm{~m}$ \\
\hline $\begin{array}{c}\text { E133 } \\
(532 \mathrm{~nm} \text { laserra })\end{array}$ & $\begin{array}{l}38(\mathrm{sh}), 1421 \mathrm{~m}, 1386 \mathrm{w}, 1357 \mathrm{~m}, 1288 \mathrm{w}, 1214 \mathrm{~m}, \\
, 755 \mathrm{vw}\end{array}$ \\
\hline $\begin{array}{c}\text { Kafeina } \\
(785 \mathrm{~nm} \text { laserra })\end{array}$ & $\begin{array}{l}1690 \mathrm{~m}, 1645 \mathrm{w}, 1600 \mathrm{~m}, 1 \\
994 \mathrm{vw}, 920 \mathrm{w}, 797 \mathrm{w}-\mathrm{m}, 73\end{array}$ \\
\hline $\begin{array}{l}\text { Azido zitrikoa } \\
\text { (785 nm laserra) }\end{array}$ & $\begin{array}{l}1726 \mathrm{w}, 1679 \mathrm{w}, 1442 \mathrm{w}, 1385 \mathrm{~m}, 1239 \mathrm{w}, 11 \\
906 \mathrm{~m}, 784 \mathrm{vs}, 792(\mathrm{sh}), 678 \mathrm{w}, 647 \mathrm{vw}, 593 \mathrm{w}, 5\end{array}$ \\
\hline $\begin{array}{c}\text { Fruktosa } \\
(785 \mathrm{~nm} \text { laserra })\end{array}$ & $\begin{array}{l}1467 \mathrm{~m}, 1423 \mathrm{w}, 1269 \mathrm{~m}-\mathrm{s}, 1239(\mathrm{sh}), 1169 \mathrm{~m}, \\
1039 \mathrm{~m}, 976 \mathrm{~m}, 920 \mathrm{~m}, 872 \mathrm{~s}, 816 \mathrm{~s}, 625 \mathrm{vs}, 589 \mathrm{~m} \text {, }\end{array}$ \\
\hline $\begin{array}{c}\text { Sakarosa } \\
(785 \mathrm{~nm} \text { laserra })\end{array}$ & $\begin{array}{l}1458 \mathrm{~m}, 1367 \mathrm{w}, 1347 \mathrm{w}, 1314 \mathrm{w}, 1243 \mathrm{~m}, 1157 \mathrm{w}, 1117 \mathrm{~s}, 1007 \mathrm{~m}, 949 \mathrm{w}, 919 \mathrm{~m}, \\
904(\mathrm{sh}), 850 \mathrm{v}, 635 \mathrm{~m}, 523 \mathrm{~m}\end{array}$ \\
\hline $\begin{array}{c}\text { Sorbitol } \\
(785 \mathrm{~nm} \text { laserra })\end{array}$ & $\begin{array}{l}1446 \mathrm{~m}, 1380 \mathrm{~m}, 1350(\mathrm{sh}), 1340 \mathrm{w}, 1250 \mathrm{~m}, 1233 \mathrm{vw}, 1138 \mathrm{~s}, 1087 \mathrm{~s}, 1075 \mathrm{vw}, \\
1061 \mathrm{~s}, 1020(\mathrm{sh}), 989 \mathrm{~m}, 930 \mathrm{~m}, 878 \mathrm{vs}, 780 \mathrm{~m}, 634 \mathrm{~m}, 507 \mathrm{~m}, 474 \mathrm{~m}, 425 \mathrm{~m}\end{array}$ \\
\hline $\begin{array}{c}\text { Glukosa } \\
\text { (785 nm laserra) }\end{array}$ & $\begin{array}{l}1459 \mathrm{~m}, 1376 \mathrm{w}, 1342 \mathrm{~s}, 1330(\mathrm{sh}), 1262 \mathrm{~m}, 1218 \mathrm{w}, 1144 \mathrm{~m}, 1120 \mathrm{vs}, 1113(\mathrm{sh}) \\
1070 \mathrm{~s}, 1066(\mathrm{sh}), 1054 \mathrm{~m}, 1014 \mathrm{w}, 1002 \mathrm{w}, 914 \mathrm{~s}, 842 \mathrm{~s}, 770 \mathrm{w}, 542 \mathrm{vs}, 405 \mathrm{vs}\end{array}$ \\
\hline $\begin{array}{r}\mathrm{C} \text { bit } \\
(785 \mathrm{~nm}\end{array}$ & $\begin{array}{l}1668 \mathrm{~s}, 1656 \mathrm{~s}, 1450 \mathrm{w}, 1487 \mathrm{vw}, 1370 \mathrm{vw}, 1321 \mathrm{~m}, 1298 \mathrm{w}, 1258 \mathrm{~m}, 1128 \mathrm{~s}, \\
1113(\mathrm{sh}), 1066 \mathrm{w}, 1028 \mathrm{w}, 991 \mathrm{vw}, 874 \mathrm{w}, 822 \mathrm{~m}-\mathrm{s}, 709 \mathrm{~m}, 699 \mathrm{~m}, 628 \mathrm{vs}, 590 \mathrm{~m}, \\
567 \mathrm{~m}-\mathrm{s}\end{array}$ \\
\hline
\end{tabular}

vs: oso indartsua; s: indartsua; m: ertaina; w: ahula; vw: oso ahula; sh: sorbalda. 
Iñaki Vázquez-de la Fuente, Nagore Prieto-Taboada, Miren Ostra-Beldarrain, Juan Manuel Madariaga

\subsection{Kalibrazioa}

Aipatu bezala, Raman espektroskopia erabiliz aldagai bakarreko kalibraketan eta aldagai anitzeko kalibraketan oinarritutako kalibratuak sortu ziren, eta ondoren bi metodoak konparatu ziren.

\subsubsection{Aldagai bakarreko erregresio lineala}

\subsubsection{1. $785 \mathrm{~nm}$-ko laserra}

785 nm-ko laserrarekin, E124 eta E122 koloratzaileen kalibraketak egin ziren, ondo definitutako espektroak eta espektro biziak lortu baitziren. 5 espektro neurtu ziren kalibrazio-puntu bakoitzeko.

E124 koloratzailearen kalibraketarako $1.361 \mathrm{~cm}^{-1}$-eko banda altuera neurtu zen, intentsitate handieneko seinalea zelako eta uhin-luzera horretan gainerako konposatuek seinalerik ematen ez zutelako. Lortutako erregresioa 1. irudian ikus daiteke, eta kalibraketaren kalitate parametroak 3. taulan jaso dira. Irudian ikus daitekeen moduan, kalibraketaren linealtasuna ez zen oso ona $\left(\mathrm{R}^{2}=0.7746\right)$, eta, gainera, nabarmentzekoa da neurrien errepikakortasuna txikia izan zela (\% 20-48 arteko doitasuna).
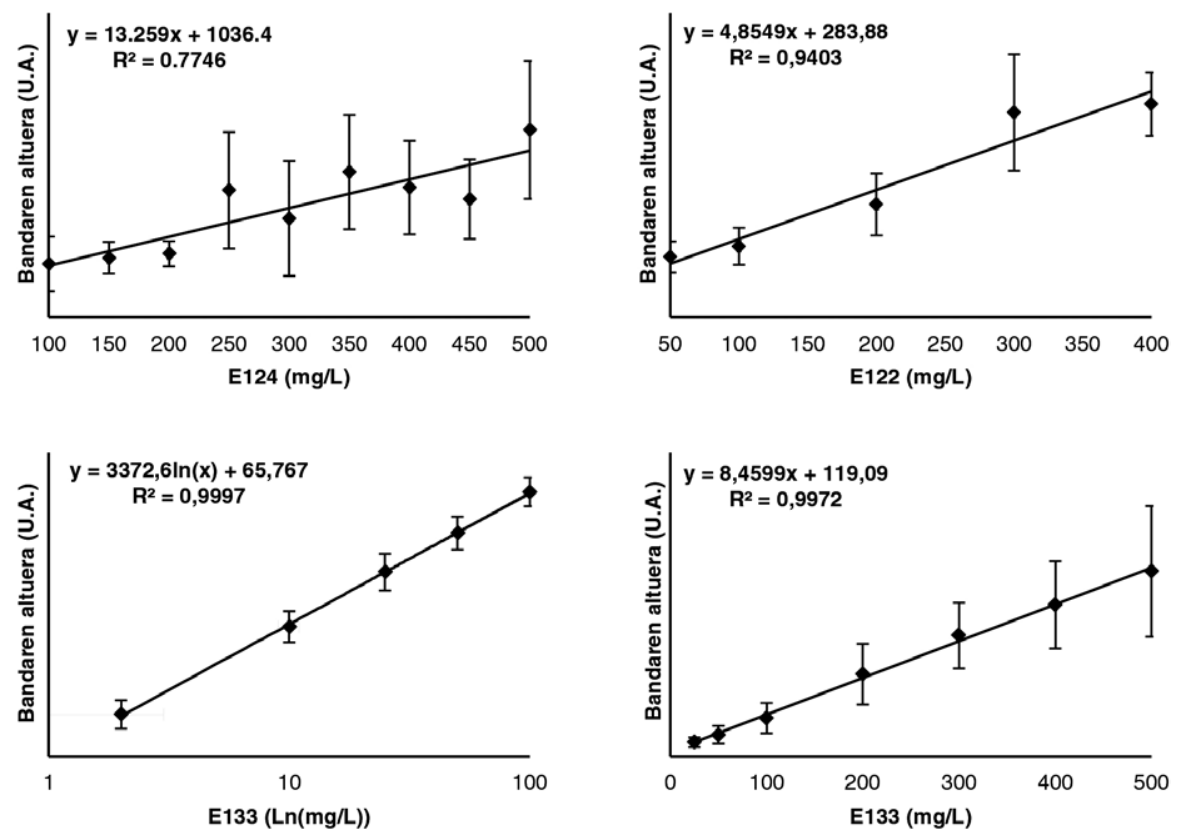

1. irudia. Raman kalibratzeko kurbak, koloratzaileen Raman banda nagusiaren altuera irudikatuz eginak: E124 $\left(1.361 \mathrm{~cm}^{-1}\right)$, E122 $\left(1.047 \mathrm{~cm}^{-1}\right)$ eta E133 $\left(1.614 \mathrm{~cm}^{-1}\right)$. E133 koloratzailerako, eraztunaren ertzean eta barruan neurtutako kalibratze-kurbak irudikatzen dira. 
E122 koloratzailearen kalibraketa lortzeko $1.047 \mathrm{~cm}^{-1}$ banda-altuera neurtu zen, eta lortutako seinalea kontzentrazioaren aurrean irudikatu zen (1. irudia). Kasu honetan, ez da erabili bandarik sendoena, baina 1. irudian ikus daitekeen moduan kalibrazio lerroa sortzeko erabil daiteke. Lortutako kalibraketaren tarte lineala 50-400 $\mathrm{mg} \mathrm{L}^{-1}$-ekoa zen, zehaztasuna $\%$ 25ekoa eta linealtasuna aurreko koloratzailearekin lortutakoa baino hobea $\left(\mathrm{R}^{2}=0,9403\right)$. Kalitate parametro hauek 3. taulan jaso dira. Garrantzitsua da azpimarratzea Raman espektroskopian kalibraketa zuzenak lortzea zaila dela, eta, beraz, balio hauek egokitzat jo daitezke bai zehaztasunerako, bai linealtasunerako ere [7].

\subsubsection{2. $532 \mathrm{~nm}$-ko laserra}

$532 \mathrm{~nm}$-ko laserrarekin E133 koloratzailearen kalibraketa bakarrik egin ahal izan zen (ondo definitutako bandak eta fluoreszentzia gutxi zituen koloratzaile bakarra da), eta horretarako, $1.614 \mathrm{~cm}^{-1}$-eko bandaren altuera neurtu zen. 2 eta $100 \mathrm{mg} / \mathrm{L}$ arteko kontzentrazio tartean egin zen kalibraketa. Kalibrazio-puntu bakoitzeko 18 neurri hartu ziren; izan ere, neurketan ikusi zen koloratzaile honekin lortutako balioen arteko desbideratze estandarra txikiagoa zela beste koloratzaileekin hartutakoak baino, eta errepikagarritasuna egiaztatu nahi izan zen,. Eraztunaren ertzean egindako kalibraketan \% 14ko batez besteko aldakuntza-koefizientea lortuz. Kasu honetan seinalea kontzentrazioaren aurrean irudikatzean joera logaritmikoa duen irudia lortu zen $\left(\mathrm{R}^{2}=0,9897\right)$. Portaera logaritmiko hau linearizatzeko asmoz kalibraketa kalkulatzeko seinale instrumentala kontzentrazioaren logaritmoaren aurrean irudikatu zen zuzenean eta modu honetan lortutako erregresio linearentzat $\mathrm{R}^{2}=0.9997$ balioa lortu zen (1. irudia). Kalibraketa honekin E133 koloratzailerentzat lortutako doitasuna ona izan zen ( $\mathrm{RSD}=\% 7$, ikus 3. taula).

Orain arte azaldutako emaitzak eraztunaren ertzean neurtutako espektroei lortutakoak dira; izan ere, literaturan adierazitakoari jarraiki, hori da eraztuna sortzeko prozesuan koloratzaile gehien pilatzen den gunea, eta, beraz, seinaleak neurtzeko gune egokiena kasu honetan. Hala ere, lortutako emaitzetan kuantifikazioaren goiko mugan (100 mg/l-tik gorako kontzentrazioetarako) linealtasuna galtzen zela ikusi zen. Horren zergatia 2. irudia aztertuz uler daiteke. Han, nabarmena da kontzentrazioa handitua ahala eraztunaren ertza handitu egiten dela; horrela, kontzentrazio txikietan laserraren eremua koloratzaileak osatzen duen eraztunaren ertza baino handiagoa da, baina kontzentrazio handietan eraztunaren ertza laserrak hartzen duen eremua baino zabalagoa da. Beraz, kontzentrazio jakin batetik aurrera seinalea ia konstante mantenduko da, eta linealtasuna galdu egingo da. 
Iñaki Vázquez-de la Fuente, Nagore Prieto-Taboada, Miren Ostra-Beldarrain, Juan Manuel Madariaga

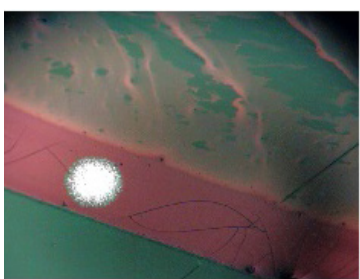

$500 \mathrm{ppm}$

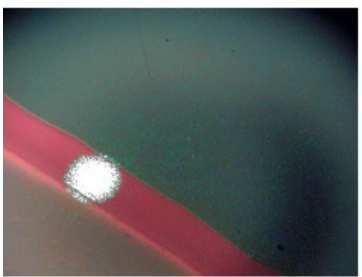

$200 \mathrm{ppm}$

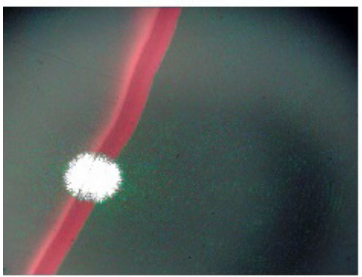

$25 \mathrm{ppm}$

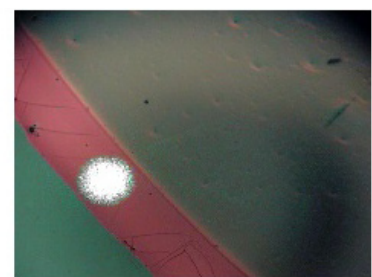

$400 \mathrm{ppm}$

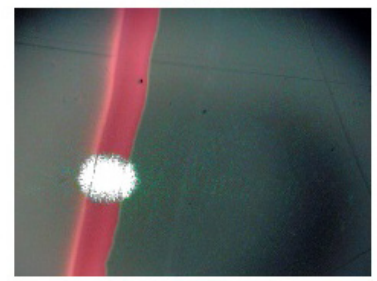

$100 \mathrm{ppm}$

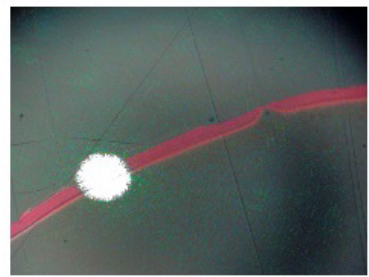

$10 \mathrm{ppm}$

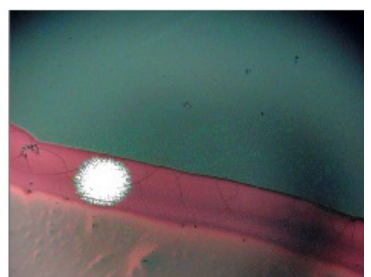

$300 \mathrm{ppm}$

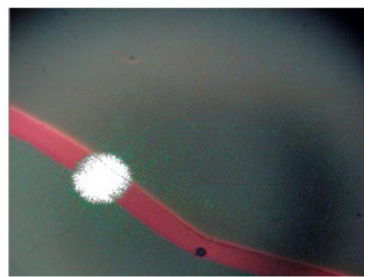

$50 \mathrm{ppm}$

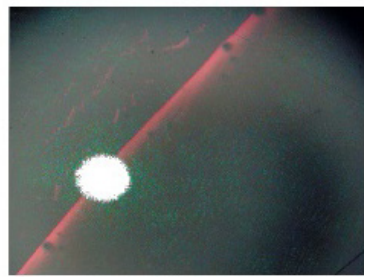

$2 \mathrm{ppm}$

2. irudia. Raman mikroskopioaren kamerarekin jasotako irudiak, non eraztunaren ertza eta laserra ikusten diren.

Hori kontuan hartuta, E133 koloratzailerako kalibraketa errepikatu zen, baina neurria eraztunaren barruan eginez; kasu honetan lortutako kalibraketaren linealtasuna oso handia da $\left(\mathrm{R}^{2}=0,9972\right)$, 1. irudian ikus daitekeen bezala. Hala ere, kasu honetan banda-altuerek desbideratze handiagoa zuten (\% 11ko batez besteko RSDa) eraztunaren ertzean neurtuta baino, eta horrek doitasuna murrizten du, eta ondorioz detekzio-muga eta kuantifikazio-muga handitzen ditu eraztunaren ertzeko kalibraketarekiko. Eraztunaren barnealdea heterogeneoagoa delako gertatzen da hori. Beraz, eraztunaren barruan neurtzeak kalibraketaren tarte lineala handitzen badu ere, esan daiteke oro har parametro analitikoetan emaitzek okerrera egin zutela.

3. taulan koloratzaile bakoitzaren erregresio linealen parametro estatistikoak alderatzen dira. Kasu guztietan jatorrizko ordenatuaren eta maldaren konfiantza-tarteak \% 95eko konfiantza-mailarekin ematen dira. Lortutako kalibraketa onena E133 koloratzailearentzat eraztunaren ertzean neurtutakoa dela esan daiteke, bai sentikortasunari, bai linealtasunari eta bai detekzio-mugari dagokionez ere. Koloratzaile honentzat lortutako LOD balioak 
literaturan koloratzaile berarentzat SERS erabiliz lortutako LOD balioekin alderatuz gero, lortutako emaitzak antzekoak dira [7, 23], gainera kasu honetan nanopartikulak erabiliz seinalea areagotu beharrik gabe. Hala eta guztiz ere, kontuan hartuz mota honetako lanetan SERS espektroskopia erabiltzen dela seinalea areagotu eta metodoen sentikortasuna handiagotzeko, kasu honetan ere SERS metodologia aplikatu da, teknika honek koloratzaileen determinazioan ekar ditzakeen onurak aztertzeko.

3. taula. Aztertutako koloratzaileentzat kalkulatutako erregresio linealen parametro estatistikoak. Konfiantza tarteak \%95eko konfiantza mailarekin adierazi dira. LOD: detekzio muga, LOQ: kuantifikazio muga.

\begin{tabular}{lcccc}
\hline & E124 & E122 & $\begin{array}{c}\text { E133 } \\
\text { eraztunaren } \\
\text { barruan }\end{array}$ & $\begin{array}{c}\text { E133 } \\
\text { eraztunaren } \\
\text { ertzean }\end{array}$ \\
\hline Laserra $(\mathrm{nm})$ & 785 & 785 & 532 & 532 \\
Tarte lineala & $100-500 \mathrm{mg} / \mathrm{L}$ & $50-400 \mathrm{mg} / \mathrm{L}$ & $25-500 \mathrm{mg} / \mathrm{L}$ & $2-100 \mathrm{mg} / \mathrm{L}$ \\
Malda & $13 \pm 6$ & $5 \pm 2$ & $8,5 \pm 0,5$ & $3.373 \pm 114$ \\
Jatorrizko ordenatua & $1.036 \pm 2.088$ & $284 \pm 553$ & $119 \pm 144$ & $66 \pm 372$ \\
$\mathrm{R}^{2}$ & 0,7746 & 0,9403 & 0,9972 & 0,9997 \\
LOD & $220 \mathrm{mg} / \mathrm{L}$ & $118 \mathrm{mg} / \mathrm{L}$ & $22 \mathrm{mg} / \mathrm{L}$ & $1,4 \mathrm{mg} / \mathrm{L}$ \\
LOQ & $666 \mathrm{mg} / \mathrm{L}$ & $358 \mathrm{mg} / \mathrm{L}$ & $66 \mathrm{mg} / \mathrm{L}$ & $1,1 \mathrm{mg} / \mathrm{L}$ \\
\hline
\end{tabular}

\subsubsection{Raman seinalea SERS bidez anplifikatzearen ebaluazioa}

Aurreko atalean kuantifikatu diren hiru koloratzaileekin egin ziren saiakerak, baina SERS efektua (ohiko Ramanen aldean espektroaren intentsitatea handitzea) soilik aurkitu zen E133 koloratzailearentzat eta $532 \mathrm{~nm}$-ko laserra erabiliz. 3. irudian, E133 koloratzailearen Raman espektroaren intentsitatearen igoera ikusten da, seinalea $10^{1}-10^{3}$ magnitude-ordena artean handitzen da, eta literaturan espero diren anplifikazioak baino igoera txikiagoa lortzen da [8].

Seinalearen intentsitatean hobekuntza lortu bada ere, SERSen egindako probek erakutsi dute ez dela espero bezain teknika erraza, alde batetik beharrezkoa delako kalitatezko nanopartikula metalikoak sintetizatzea, eta beste aldetik SERS efektuaren agerpena aztertu beharreko laserraren eta substratuaren baldintzen menpekoa delako. Gainera, kalibraketa egiteko aukera ez da sinplea; izan ere, badirudi koloratzaileen seinalean lortutako intentsitate-gehikuntza ez dela berdina koloratzaile kontzentrazio guztientzat, eta horrek linealtasunaren galera dakar. Beraz, metodoa modu sistematikoan optimizatu beharko litzateke nanopartikulen/disoluzioaren nahasketaren proportzioak aldatuz eta laserraren baldintzak doituz; literaturan aipatzen diren kalibraketa errepikakor eta sentikorrak sortu ahal iza- 
teko [8]. Honenbestez, SERS egin gabe lortutako emaitzak onak izan direla ikusirik eta lanaren helburua analisi kuantitatiborako metodologia erraza proposatzea dela kontuan hartuz, lanaren lerro hau bere horretan uztea erabaki zen.

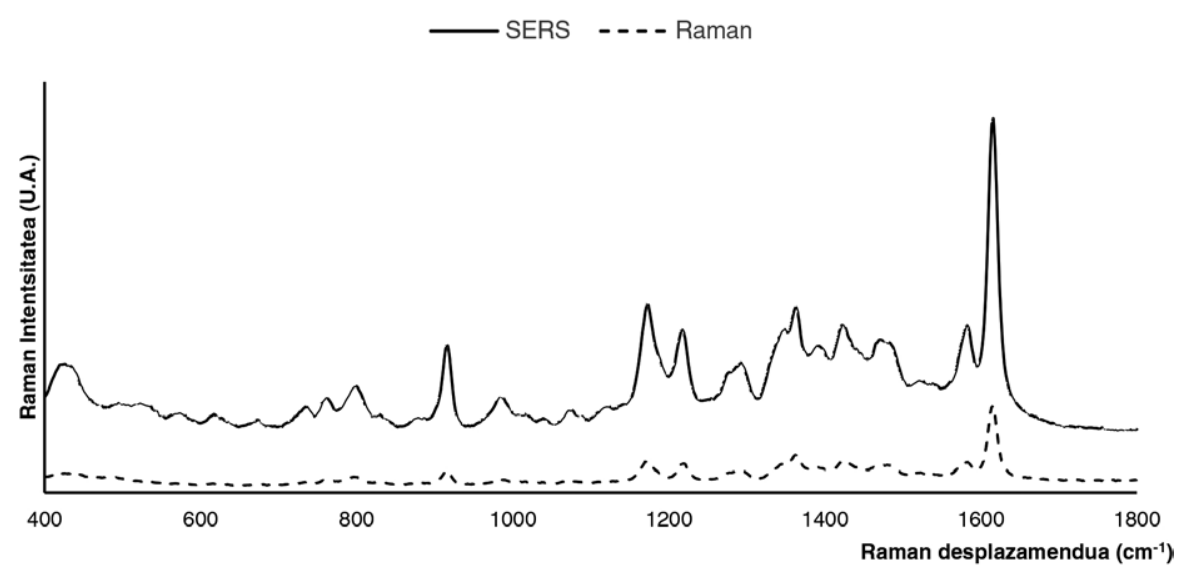

3. irudia. E133 koloratzailearentzat neurtutako Raman eta SERS espektroak. Han ikus daiteke SERS efektuaren ondorioz koloratzailearen seinalean eragindako handitzea.

\subsubsection{Aldagai anitzeko kalibrazioa}

\subsubsection{Osagai nagusien analisia (PCA)}

Aldagai bakarreko analisian, espektroak bisualki aztertu ziren, analizatu beharreko analitoen bandak eta interferentzia sor dezaketen gehigarrien bandak konparatuz. Aldagai anitzeko analisiaren kasuan, gerta zitezkeen interferentzien azterketa egiteko osagai nagusien analisia erabili zen. Horretarako, koloratzaile eta gehigarrien espektroekin datu matrizea osatu eta PCA analisi burutu zen, hasiera batean Raman espektro gordinak erabiliz. Lortutako lehen PCA ereduetan ikusi zen azaldutako bariantzaren zati handi bat espektroetan jasotako fluoreszentzia-efektuari zegokiola, eta, beraz, ezinbestekoa zela datuen aurretratamendua egitea. Hainbat aurretratamendu burutu ondoren, ikusi zen espektroetan oinarri-lerroaren zuzenketa eta SNV (Standard Normal Variate) aurretratamenduak aplikatu ondoren koloratzaileak eta gainerako elikagai-gehigarriak ongi bereizten zirela PCA eredu batekin (4. irudia). 


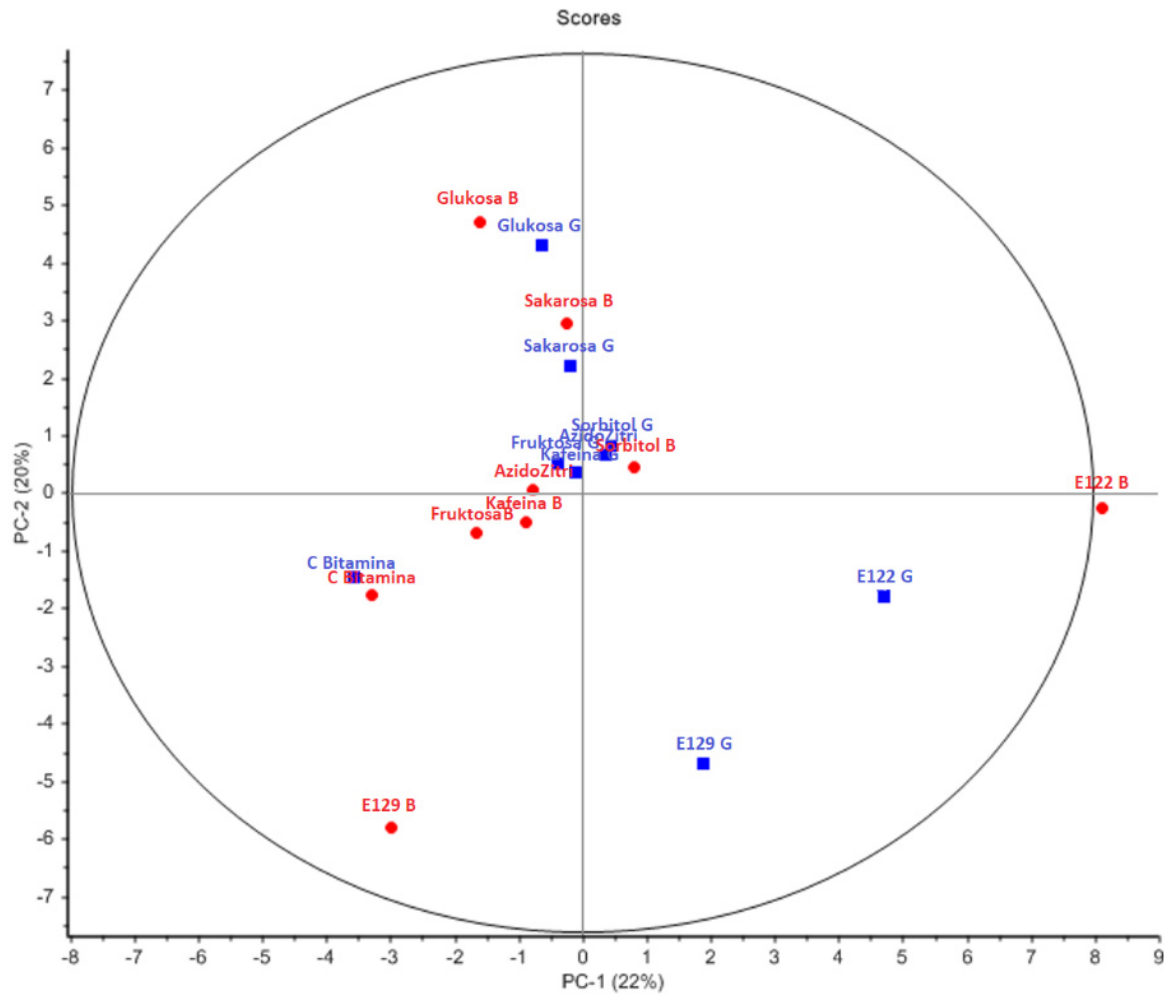

4. irudia. Koloratzaileei eta bestelako gehigarriei bi laser ezberdinekin lortutako espektro multzoarekin egindako PCA ereduaren scores grafikoa. Espektro guztiei «maximum normalization» aurretratamendua egin zaie.

\subsubsection{Kalibrazioa}

Aurretik esan bezala, lan honetan PLS algoritmoa erabili zen E133 koloratzailearen determinazioa egiteko garaian aldagai anitzeko kalibraketaren aukerak aztertzeko asmoz. Horretarako, 475 eta $1.035 \mathrm{~cm}^{-1}$ arteko espektroak erabili dira E133 2 eta $500 \mathrm{mg} / \mathrm{L}$ kontzentrazio tartean. Lortutako PLS ereduarekin lortutako emaitzak 5.a irudian ikus daitezke; han, PLS ereduarekin analizatutako laginentzat lortutako kontzentrazioak irudikatzen dira kontzentrazio teorikoaren aurrean. Lortutako erregresioaren linealtasuna nahiko ona da $\left(\mathrm{R}^{2}\right.$ kalibratua $=0,925$ eta $\left.\mathrm{R}_{\text {balidazioa }}=0,905\right)$; batez besteko errore koadratikoaren erroa $\left(\mathrm{RMSE}_{\text {kalibratua }}=47,6\right.$ eta $\left.\mathrm{RMSE}_{\text {balidazioa }}=55,3\right)$ baxu mantendu zela esan daiteke (\% 10 inguru, batez beste). Balidazio-zuzenak kalibrazio-zuzenaren oso antzeko malda izan zuen, eta eredua azaltzeko 3 faktore baino ez ziren behar izan. Nabarmendu behar da beste uhin-luzera tarte batzuk ere erabili zirela: adi- 
Iñaki Vázquez-de la Fuente, Nagore Prieto-Taboada, Miren Ostra-Beldarrain, Juan Manuel Madariaga

(a)

Iragarri vs Erreferentzia

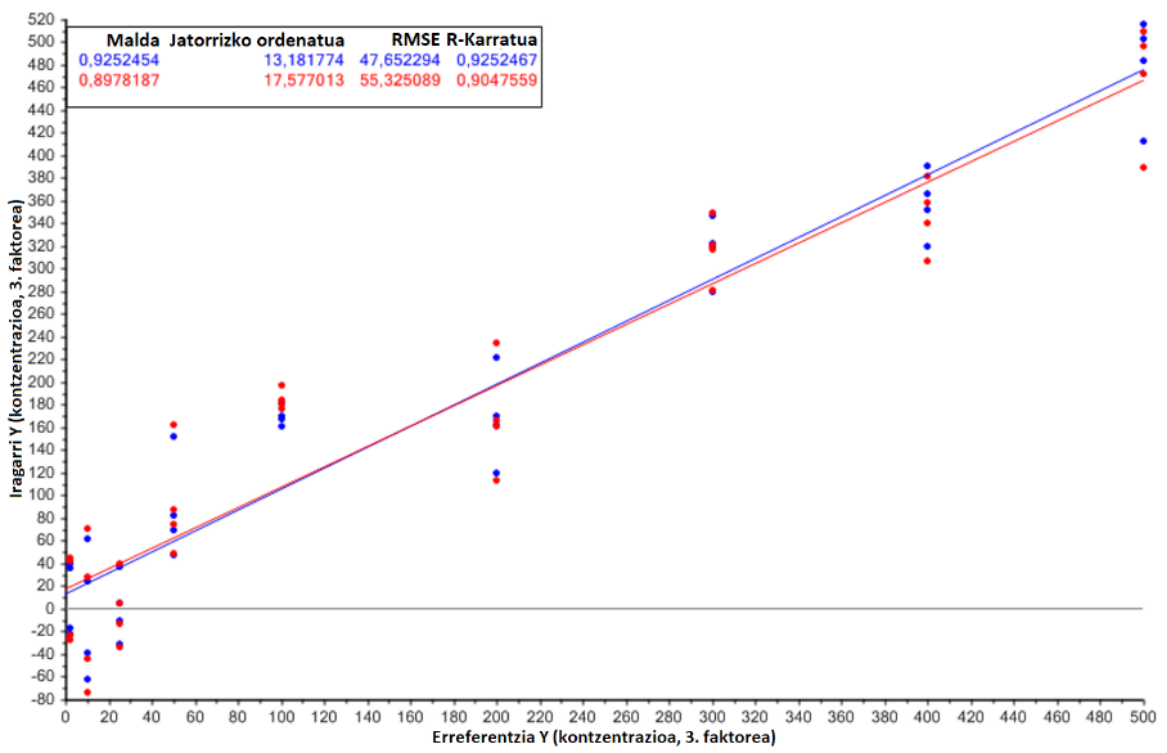

(b)

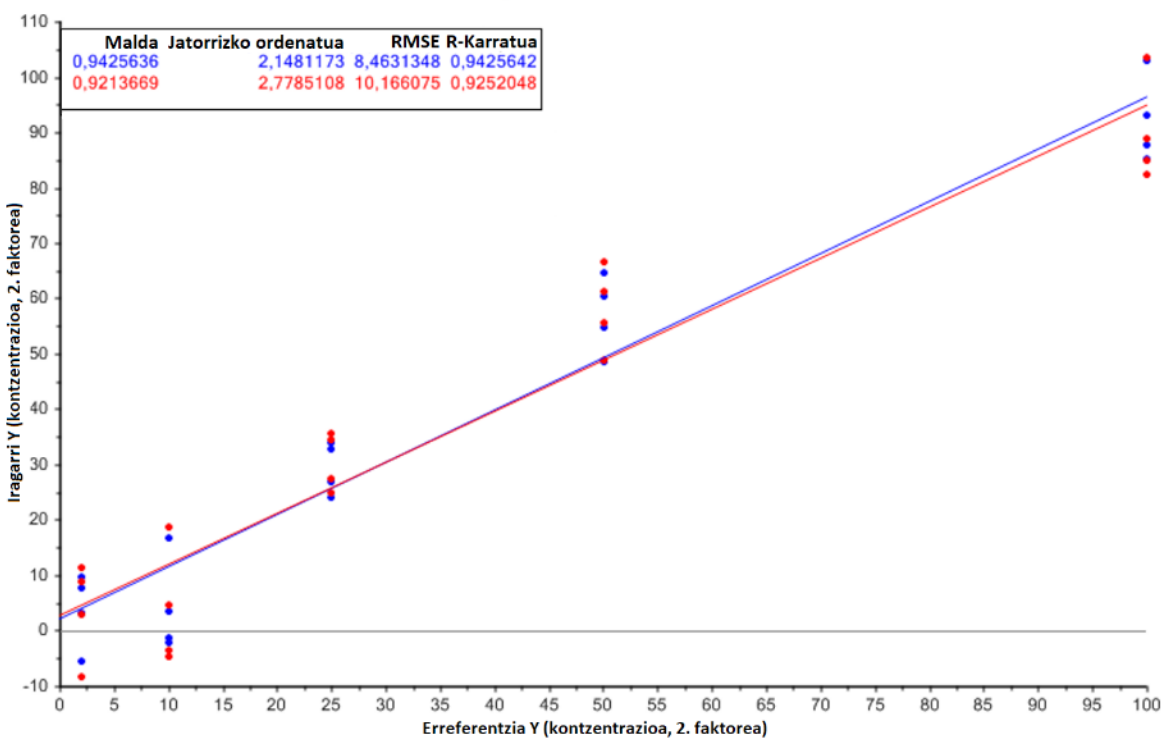

5. irudia. E133 koloratzailearentzat lortutako PLS ereduei dagozkion «Predicted vs Reference» irudiak. (a) Erabilitako espektroak: $475-1.035 \mathrm{~cm}^{-1}$ tartekoak, eraztunaren ertzean neurtuak. (b) Erabilitako espektroak: 216-1.800 $\mathrm{cm}^{-1}$ tartekoak, eraztunaren ertzean neurtuak. Kontzentrazio tartea 2-100 $\mathrm{mgL}^{-1}$. 
bidez, 216 eta $1.800 \mathrm{~cm}^{-1}$ arteko tartearekin 5 faktore behar ziren eredua azaltzeko, eta, beraz, ondorioztatu zen espektroaren zati batzuek informazio hobea ematen dutela beste batzuek baino koloratzaile kontzentrazioari dagokionez.

Aldagai bakarreko kalibraketa eta aldagai anitzeko kalibraketa alderatzeko, tarte lineala $2 \mathrm{mg} / \mathrm{l}$-tik $100 \mathrm{mg} / \mathrm{l}-\mathrm{ra}$ murriztu zen (5.b irudia). Kasu honetan kalibrazio-ereduaren emaitzak hobetzen dira $\left(\mathrm{R}^{2}\right.$ kalibratua $=0,943$ eta $\mathrm{R}^{2}$ balidatzea $\left.=0,925\right)$, eta lortutako RMSE erroreak baxuagoak dira $\left(\mathrm{RMSE}_{\text {kalibratua }}=8.46\right.$ eta $\left.\mathrm{RMSE}_{\text {balidazioa }}=10.2\right)$. Dena den, kontuan hartu behar da jaitsiera hau ez dela hain adierazgarria, errore hauek absolutuak direlako eta kontzentrazioak baxuagoak izanik hori espero zitekeelako. Balidazio-zuzenaren malda kalibraziokoaren oso antzekoa zen, eta bi faktore baino ez ziren behar izan eredua azaltzeko. Beraz, aldagai bakarreko kalibraketaren kasuan bezala, emaitza hobeak lortzen dira kontzentraziotartea murrizten bada. Bestalde, aldagai bakarreko kalibraketa eta PLS bidez lortutako kalibraketa ereduekin lortutako emaitzak alderatzen baditugu, oro har esan daiteke aldagai bakarra erabiliz lortutako kalitate-parametroak apur bat hobeak direla.

4. taula. E133 koloratzailearen determinaziorako PLS ereduen ezaugarriak.

\begin{tabular}{lcc}
\hline Tarte lineala & $2-500 \mathrm{mg} / \mathrm{L}$ & $2-100 \mathrm{mg} / \mathrm{L}$ \\
Jatorrizko aldagai kopurua & 561 & 1.585 \\
Aldagai sorrak (Latent Variables, LV) & 3 & 2 \\
$\mathrm{R}^{2}{ }_{\text {kal }} / \mathrm{R}^{2}$ bal & $0,9425 / 0,9252$ & $0,9426 / 0,9252$ \\
$\mathrm{RMSE}_{\mathrm{kal}} / \mathrm{RMSE}_{\mathrm{cv}}$ & $47,6 / 55,3$ & $8,46 / 10,17$ \\
\hline
\end{tabular}

Azkenik, sortutako kalibraketa ereduen azken konparaketa egiteko asmoz, E133 koloratzailearen determinazioa egin zen laborategian prestatutako lagin ezezagun batean lortutako bi kalibratu onenekin (eraztunaren ertza eta $2-100 \mathrm{mg} / \mathrm{L}$ bi kasuetarako). Lagin ezezagunaren espektroa neurtuz eta kalibraketak erabiliz lortutako kontzentrazioak t proba baten bidez konparatu ziren (\% 95eko konfiantzan), tkalkulatuta <tkritikoa (tkalkulatuta $=1.0147$ ) lortuz; beraz, ez zen ezberdintasun adierazgarririk aurkitu. Hala eta guztiz ere, azpimarratu behar da PLS bidezko kalibraketa askoz ere azkarragoa izan zela, banden altuerak eskuz integratu beharrik ez zegoelako, denbora murriztuz eta errepikakortasuna hobetuz. Eskuz integratzeak dakarren desabantaila gainditu daiteke prozedura hau automatizatzeko adibidez Matlab ${ }^{\circledR}$ programa erabiliz. 
Iñaki Vázquez-de la Fuente, Nagore Prieto-Taboada, Miren Ostra-Beldarrain, Juan Manuel Madariaga

\section{ONDORIOAK}

Raman espektroskopiak elikagai-koloratzaile desberdinak identifikatu eta kuantifikatzeko duen erabilgarritasuna aztertu da. Horretarako, koloratzaile bakoitzarekin erabiltzeko laserrik onena identifikatu zen eta koloratzaile batzuen eta beste elikagai gehigarri batzuen espektroen liburutegia osatu da.

Ondoren, E124 eta E122 koloratzaileen determinaziorako lehen hurbilketa bat egitea lortu da $785 \mathrm{~nm}$-ko laserra erabiliz, banden altuera eta koloratzaile kontzentrazioaren artean erlazio lineala lortuz. Bestalde, $532 \mathrm{~nm}$-ko laserra erabiliz E133 koloratzailearen determinaziorako aldagai bakarreko eta aldagai anitzeko kalibraketa ereduak kalkulatu dira. Bi kasuetan emaitza onak lortu dira linealtasunari dagokionez $\left(\mathrm{R}^{2}>0.90\right)$, eta lortutako zehaztasun- eta detekzio-mugak teknika honekin ohikoak diren balioetan sartu dira.

SERS efektuari dagokionez, E133 koloratzaileren Raman seinalearen intentsitatea handitu zela ikusi da zilar nanopartikulen presentzian, baina ez da lortu seinalearen eta kontzentrazioaren arteko erlazio linealik. SERS efektuaren erreproduzigarritasuna hobetzeko, urre nanopartikulak aztertzea aukera bat izan daiteke, bai eta beste sintesi bide batzuk ikertzea ere.

Kimiometria erabiltzeak koloratzaileen analisia oztopatu dezaketen parametro instrumentalak identifikatzea ahalbidetu du. Espektroak PCA bidez analizatzean agerian geratu da fluoreszentziak koloratzaile eta gehigarrien espektroan duen eragin handia eta datuen aurretratamendu egokiak duen garrantzia. Bestalde, E133 koloratzailearen determinaziorako PLS algoritmoa aplikatu denean, ez da hobekuntza nabarmenik lortu espektroen eskuzko integratzea saihesteak dakarren erosotasunaz haratago.

Hori guztia kontuan hartuta, eta kontuan hartuz Europar Batasunak E133 koloratzailearentzat fruta eta barazkietan ezarritako gehieneko dosia $200 \mathrm{mg} / \mathrm{L}$ dela [10], eta koloratzaile honentzat lan honetan lortutako LOQ $1,1 \mathrm{mg} / \mathrm{L}$ dela, ondoriozta daiteke Raman espektroskopia elikagai-koloratzaileak kuantifikatzeko etorkizun handiko teknika dela.

\section{ESKER ONAK}

Lan honek DEMORA (PID2020-113391GB-I00) diru-laguntza jaso du, estatuko ikerketa-agentziak finantziatzen duena. 


\section{BIBLIOGRAFIA}

[1] Elikagai-gehigarriak. Eskuragarri: https://webgate.ec.europa.eu/foods_system/main/?sector=FAD\&auth=SANCAS. 2021.

[2] Parlamento Europeo. 2019. «Réglamento (UE) 2019/800 de la comisión». 1331-1333.

[3] Anastasaki, E. G., Kanakis, C. D., Pappas, C., Maggi, L., Zalacain, A., Carmona, M., Alonso, G. L. eta Polissiou, M. G. 2010. "Quantification of crocetin esters in saffron (Crocus sativus L.) using Raman spectroscopy and chemometrics». J. Agric. Food Chem., 58, 6011-6017.

[4] Bendoula, R., Gobrecht, A., Moulin, B., Roger, J. M. eta Bellon-MauREL, V. 2015. «Improvement of the chemical contentprediction of a model powder system by reducing multiple scattering using polarized light spectroscopy». Appl. Spectrosc., 69, 95-102.

[5] Hosker, B. S. 2018. «Demonstrating Principles of Spectrophotometry by Constructing a Simple, Low-Cost, Functional Spectrophotometer Utilizing the Light Sensor on a Smartphone». J. Chem. Educ., 95, 178-181.

[6] Albizu, G., Berasarte, I., Bordagaray, A., Dávila, S., eta Jaime, E. 2021. «Irudi Digitalen Analisia: espektrofotometroa ordezkatzen». EKAIA Euskal Herriko Unibertsitateko Zientzia eta Teknologia Aldizkaria, 39, 189-209.

[7] Gukowsky, J. C., Xie, T., GaO, S., Qu, Y. eta He, L. 2018. «Rapid identification of artificial and natural food colorants with surface enhanced Raman spectroscopy». Food Control, 92, 267-275.

[8] Yao, Y., Wang, W., Tian, K., Ingram, W. M., Cheng, J., Qu, L., Li, H., HAN, C. 2018. «Highly reproducible and sensitive silver nanorod array for the rapid detection of Allura Red in candy». Spectrochim. Acta-Part A Mol. Biomol. Spectrosc., 195, 165-171.

[9] Lohumi, S., Lee, H., Kim, M.S., Qin, J., Kandpal, L. M., Bae, H., Rahman, A., CHO, B. K. 2018. «Calibration and testing of a Raman hyperspectral imaging system to reveal powdered food adulteration». PLoS One, 13, 1-17.

[10] Parlamento Europeo. 2011. «Réglamento (UE) 1129/2011 de la comisión».

[11] Almeida, M. R., Stephani, R., Santos, F. Dos eta Oliveira, L. F. C. De. 2010. «Spectroscopic and Theoretical Study of the «Azo»-Dye E124 in Condensate Phase: Evidence of a Dominant Hydrazo Form». J. Phys. Chem., 114, 526-534.

[12] Costantini, I., Veneranda, M., Prieto-Taboada, N., Bellot-Gurlet, L., eta MANUEL, J. 2016. «Comparison of semiquantification experimental methodologies using micro-Raman spectroscopy: PALME software as an alternative tool for the study of salt efflorescence». Journal of Raman Spectroscopy, 42, 1415-1421

[13] Rygula, A., Majzner, K., Marzec, K. M., Kaczor, A., PilarczyK, M., eta BARANSKA, M. 2013. «Raman spectroscopy of proteins: a review». Journal of Raman Spectroscopy, 44, 1061-1076. 
[14] Czamara, K., Majzner, K., Pacia, M. Z., Kochan, K., Kaczor, A., eta BaRANSKA, M. 2014. «Raman spectroscopy of lipids: a review». Journal of $R a-$ man Spectroscopy, 46, 4-20.

[15] Potgieter-Vermaak, S., Maledi, N., Wagner, N., Van Heerden, J. H. P., Van Grieken, R., eta Potgieter, J. H. 2011. «Raman spectroscopy for the analysis of coal: a review». Journal of Raman Spectroscopy, 42, 123-129.

[16] D. BERSANI, P.P. LOTTICI, 2016 Raman spectroscopy of minerals and mineral pigments in archaeometry, J. Raman Spectrosc., 47, 499-530.

[17] P. Vandenabeele. 2013. Practical Raman spectroscopy: an introduction, Wiley, Chichester (UK).

[18] R.S. Das, Y. K. Agrawal. 2011 «Raman spectroscopy: Recent advancements, techniques and applications». Vib. Spectrosc., 57163-176.

[19] UCL ChEMISTRY. Available at: http://www.chem.ucl.ac.uk/resources/raman/. 2010.

[20] Bonsak, J., Mayandi, J., Thøgersen, A., Stensrud Marstein, E. eta MaHALINGAM, U. 2011. «Chemical synthesis of silver nanoparticles for solar cell applications». Phys. Status Solidi Curr. Top. Solid State Phys., 8, 924927.

[21] Solomon, M. M., eta Umoren, S. A. 2016. «In-situ preparation, characterization and anticorrosion property of polypropylene glycol/silver nanoparticles composite for mild steel corrosion in acid solution». Journal of Colloid and Interface Science, 462, 29-41.

[22] Wei, D., Chen, S., eta Liu, Q. 2015. «Review of Fluorescence Suppression Techniques in Raman Spectroscopy». Applied Spectroscopy Reviews, 50, 387-406.

[23] Ai, Y. Jie, Liang, P., Wu, Y. X., Dong, Q. M., Li, J. B., BaI, Y., Xu, B. J., YU, Z. eta NI, D. 2018. «Rapid qualitative and quantitative determination of food colorants by both Raman spectra and Surface-enhanced Raman Scattering (SERS)». Food Chem., 241, 427-433. 